\title{
Unique contribution of one patient advocacy organization in advancing cerebral cavernous malformation awareness and research
}

\section{Cornelia Lee}

Angioma Alliance, Charlottesville, Virginia 22901, USA.

Correspondence to: Dr. Cornelia Lee, Angioma Alliance, 977 Seminole Trail, \#367, Charlottesville, Virginia 22901, USA. E-mail: clee@angiomaalliance.org

How to cite this article: Lee C. Unique contribution of one patient advocacy organization in advancing cerebral cavernous malformation awareness and research. Vessel Plus 2022;6:7. https://dx.doi.org/10.20517/2574-1209.2021.31

Received: 19 Feb 2021 First Decision: 17 Mar 2021 Revised: 25 Mar 2021 Accepted: 8 Apr 2021 Published: 17 Feb 2022

Academic Editor: Jun Zhang Copy Editor: Yue-Yue Zhang Production Editor: Yue-Yue Zhang

\begin{abstract}
Advocacy organizations have long played a role in advancing care and research for patients affected by rare disease. Angioma Alliance has served traditional functions of organizing scientific meetings and creating shared resources like a tissue bank and a patient registry. Uniquely, the organization has employed creative patient engagement methods like subsidized genetic testing as well as targeting special populations to expand research participation and understanding of the illness. Special populations include those with CCM3 mutations, the CCM1 Common Hispanic Mutation, and Black patients.
\end{abstract}

Keywords: Cavernous, angioma, malformation, cavernoma, advocacy, cerebrovascular disorders, patient cohorts, patient community, Hispanic, founder mutation

\section{INTRODUCTION}

Angioma Alliance was founded in 2002 to serve the cerebral cavernous malformation (CCM) patient and research community. Over the course of the past 18 years, the organization has grown from a mother's kitchen table to an international partner in the work toward better treatments. The organization does not fund research directly; rather the focus is on creating shared resources for researchers and for patients with a special focus on expanding, engaging, and characterizing the patient base. 


\section{CHARACTERIZING THE PATIENT COMMUNITY}

While Angioma Alliance serves the research community directly through its annual scientific meeting, tissue bank, and patient registry, the organization views its most critical role as that of growing and characterizing the known patient cohort with the goal of offering researchers and industry a critical resource they might not be able to access independently. In 2009, replicating the efforts of many organizations, Angioma Alliance launched a self-report patient registry that allows for efficient communication to prospective clinical research participants. Beginning in 2016, Angioma Alliance enhanced its patient outreach program by offering free clinical diagnostic genetic testing to those with multiple lesions that could not be explained by a developmental venous anomaly or history of radiation. CCM is the result of an autosomal dominant loss-of-function mutation on any one of three genes: CCM1 (KRIT1), CCM2, or $\mathrm{CCM} 3$ (PDCD10) and can also be sporadic. A well-characterized patient cohort allows for a cleaner analysis of between-group differences with less expense to any individual research project. To date, the Angioma Alliance program has provided testing to more than 120 non-Hispanic index patients, representing well over 600 total patients once affected family members are considered, and 290 patients at-risk for the CCM1 Common Hispanic Founder Mutation, representing more than 1000 total patients (more on this below). It is believed that the Angioma Alliance program was the second-ever rare disease genotyping effort driven by a patient advocacy organization; the first was offered by DuchenneConnect. More information on Angioma Alliance programs is available at https://www.angioma.org.

\section{EXCEPTIONALLY AGGRESSIVE CCM3 SYNDROME}

Characterizing the patient cohort had precedent at Angioma Alliance as part of an outreach effort to special populations. Before the biology of CCM3 mutations was well understood, it was clear to the patient population and some providers that mutation of $\mathrm{CCM} 3$ resulted in proportionally more symptomatic children who had a greater disease burden than those with the other genetic mutations ${ }^{[1]}$. To assist in phenotyping, from 2012 to 2016, Angioma Alliance joined with cerebrovascular neurosurgeon Issam Awad at the University of Chicago to create a $\mathrm{CCM}_{3}$ Clinic at which every known patient could be seen, and their travel and excess medical expenses were covered by the organization. By 2015, examinations at the CCM3 Clinic confirmed a more aggressive, multi-systemic phenotype ${ }^{[2]}$. The finding allowed us to identify a particular phenotype that should receive high priority for genetic testing - children with greater than 5 lesions, particularly those with no CCM family history as 50\% of cases seen at the CCM3 Clinic were de novo. Adults with high lesion burden, co-morbid benign brain tumors, and/or a history of scoliosis are also prioritized. A significant amount of subsequent basic research has confirmed the uniqueness of CCM3 mutations, including the impairment of goblet cells in the gut ${ }^{[3]}$. This 2017 finding points to the possibility that individuals with $\mathrm{CCM} 3$ mutations may derive greater benefit from dietary changes, especially if made early. Finally, in addition to extensive phenotyping, the CCM3 Clinic allowed families to form close bonds with each other, ensuring a growing, invested patient community that is primed for clinical trials.

\section{A COMMON HISPANIC FOUNDER MUTATION HISTORY \& COMMUNITY}

In 2017, Angioma Alliance began its most ambitious special population outreach to address the need to engage those affected by the Common Hispanic Mutation, a founder mutation ${ }^{[4]}$ originating in the early 1600s in Mexico and New Mexico. The organization had been working in New Mexico since 2006 with only moderate success in expanding patient participation in research or educational activities. Statistically, it is expected that 30,000-40,000 individuals with the Common Hispanic Mutation continue to live in New Mexico and surrounding states, but in 2016, only 300 patients were enrolled in clinical research programs at the University of New Mexico (personal communication with Dr. Leslie Morrison, pediatric neurologist and UNM Vice Chancellor emeritus). A rare disease elsewhere, CCM is a public health issue in New Mexico. However, it was thought that mistrust of the medical system and a focus on a potentially 
devastating disease made it difficult to expand our base.

Around the same time, Angioma Alliance member and amateur genealogist Joyce Gonzales, working with professional genealogist Henrietta Christmas, identified Cristóbal Baca and Ana Morena de Lara as a founding family of the Common Hispanic Mutation in New Mexico. Angioma Alliance came to understand that Hispanic New Mexicans, whose ancestors lived along the Camino Real de Tierra Adentro before the landing at Jamestown, were intensely interested in family history and genealogy. It was also clear that the state lacked medical resources; most of the state is rural, and it ranks 49th in the percent of the population living under the poverty line. A three-pronged approach was necessary for addressing these issues and developing a novel, culturally congruent program.

\section{THE BACA FAMILY HISTORICAL PROJECT}

Angioma Alliance christened the Baca Family Historical Project (BFHP), an initiative led by a community engagement specialist and a genealogist. The initiative's name was chosen to reflect a shift from a medical model toward a culturally relevant model. BFHP hosted family conferences for the public in historical and community venues. These workshops included presentations on New Mexico and Baca family history, Baca genealogy, the connection of the CCM1 Common Hispanic Mutation to the Baca family, and, finally, information about symptoms, diagnosis and ongoing care for the illness. After the presentations, attendees could participate in family tree workshops during which they received assistance from genealogists in attendance in finding their Baca family connections. If individuals were deemed to be in a high-risk family line, they were offered onsite Oragene swab genetic testing, with results sent to the doctor designated by the individual. Those who received positive results had follow-up calls with Angioma Alliance. The organization connected them with the Angioma Alliance-recognized CCM Center of Excellence at the University of New Mexico for care and potential research participation. Over the course of three years, BFHP hosted 87 public conferences with a total of 8734 attendees. The annual CCM patient caseload at UNM rose from 30 patients per year to over 300 patients per year.

Because the backbone of New Mexico's health system is the lay Community Health Worker (CHW), or promotora, BFHP partnered with the New Mexico Department of Health to train 1060 CHWs. Once they became familiar with the illness and its connection to the Baca family line, they could refer their at-risk community members to BFHP for genealogical research and genetic testing and to UNM for care. CHWs were also able to reach families on tribal lands where the Common Hispanic Mutation had been introduced centuries earlier through the cultural trauma of kidnapping and rape at the hands of Spanish settlers. These are very sensitive conversations that only tribal community members could initiate.

BFHP engaged in a large-scale public awareness campaign soliciting coverage in newspapers and on radio and television. This work became paramount during the final, pandemic year of the initiative when no live trainings or workshops could be held. Over the course of four years, CCM education was on the airwaves around the state, including 90-min feature segments broadcast on key public and talk radio stations, reaching hundreds of thousands of readers, listeners, and viewers. It is now rare to find Hispanic individuals in New Mexico who have not heard of the historic Baca family and their connection to the Common Hispanic Mutation. Over the course of the four years, BFHP family tree workshops led to the discovery of an earlier Spanish Mexican couple, Juan Bartolome Dominguez (1596-1656) and Elena de Mendoza, whose descendants married into the Baca family and are likely the source of the Common Hispanic Mutation in the state of Chihuahua, Mexico. 


\section{ADDRESSING BARRIERS TO BLACK PATIENT ENGAGEMENT}

At the end of 2020, Angioma Alliance's BFHP transitioned its programs to the New Mexico Department of Health, the University of New Mexico, and the New Mexico Chapter of Angioma Alliance. This transition was intentional and allowed Angioma Alliance to begin a new special population outreach program targeted at Black patients around the United States. Unlike the Common Hispanic Mutation in the Southwest and the CCM2 Exon 2-10 Deletion ${ }^{[5]}$ among White families with origins in the Southeastern United States, there is to our knowledge, no founder mutation or increased prevalence of the illness among Black Americans. Nevertheless, surveying our major national clinical databases, we have found Black patients to be significantly underrepresented. For example, in the Angioma Alliance patient registry, 16 of approximately 1500 registrants self-identified as African American ( $1 \%$ of the cohort). In the United States, $\sim 13 \%$ of the population self-identify as Black. Additionally, these patients have, on average, higher Modified Rankin Scores, indicating greater disability at the time of registration. Clinical research and clinical trials should reflect the composition of the patient population and this cannot be the case with current database demographics. In the last ten years, the number of druggable CCM targets has multiplied, increasing the potential for multiple simultaneous clinical trials. In keeping with FDA's guidance on enhancing the diversity of clinical trial populations ${ }^{[6]}$, Angioma Alliance would like each clinical trial cohort to reflect the diversity of the CCM patient population. CCM patients require treatments that are shown to be safe and effective for all. To achieve this, our outreach efforts need modification.

To this end, Angioma Alliance is launching another large-scale outreach effort. The organization plans to create support groups and programming specific to Black patients, assist clinical researchers in analyzing their cohorts for between-group differences based on race, partner with larger non-profit disease-focused organizations to reduce healthcare disparities, and create a network of public hospital sister institutions that will have the opportunity to access training and expertise at our CCM Centers of Excellence. The ultimate goals are to develop a thriving, active community of engaged Black patients and families, improve care at institutions that are most likely to see these patients, decrease under-representation in clinical databases and in research participation, and disseminate information about our outreach model to other rare disease organizations so that the 4.3 million Black Americans with rare diseases can be better served.

\section{CONCLUSION}

Patient advocacy organizations can serve the research community directly, but they also have a large role to play in fostering a growing, engaged, well-characterized patient base to support clinical research including clinical drug trials. Traditional medical model outreach may not be the best method to reach all populations. Angioma Alliance has crafted targeted, culturally congruent outreach to improve the ability of clinical researchers to recruit participants who reflect the demographics of the entire CCM patient community.

\section{DECLARATIONS}

\section{Authors' contributions}

The author contributed solely to the article.

\section{Availability of data and materials}

Not applicable.

\section{Financial support and sponsorship}

Cornelia Lee is supported by Julian Grace Foundation, Global Genes, and Con Alma Health Foundation. 


\section{Conflicts of interest}

The author declared that there are no conflicts of interest.

\section{Ethical approval and consent to participate}

Not applicable.

\section{Consent for publication}

Not applicable.

\section{Copyright}

(c) The Author(s) 2022.

\section{REFERENCES}

1. Gault J, Sain S, Hu LJ, Awad IA. Spectrum of genotype and clinical manifestations in cerebral cavernous malformations. Neurosurgery 2006;59:1278-84; discussion 1284-5. DOI PubMed

2. Shenkar R, Shi C, Rebeiz T, et al. Exceptional aggressiveness of cerebral cavernous malformation disease associated with PDCD10 mutations. Genet Med 2015;17:188-96. DOI PubMed PMC

3. Tang AT, Sullivan KR, Hong CC, et al. Distinct cellular roles for PDCD10 define a gut-brain axis in cerebral cavernous malformation. Sci Transl Med 2019;11:eaaw3521. DOI PubMed PMC

4. Gunel M, Awad IA, Finberg K, et al. A founder mutation as a cause of cerebral cavernous malformation in Hispanic Americans. $N$ Engl J Med 1996;334:946-51. DOI PubMed

5. Liquori CL, Berg MJ, Squitieri F, et al. Deletions in CCM2 are a common cause of cerebral cavernous malformations. Am J Hum Genet 2007;80:69-75. DOI PubMed PMC

6. U.S. Food \& Drug Administration. Enhancing the diversity of clinical trial populations - eligibility criteria, enrollment practices, and trial designs guidance for industry, November 2020. Available from: https://www.fda.gov/regulatory-information/search-fda-guidancedocuments/enhancing-diversity-clinical-trial-populations-eligibility-criteria-enrollment-practices-and-trial [Last accessed on 2 Nov 2021]. 